\title{
An analytical multicriteria model based on graph theory for reliability enhancement in distribution electrical networks
}

\author{
A. Lekbich', A. Belfqih ${ }^{2}$, T. Ouderhman ${ }^{3}$, J. Boukherouaa $^{4}$, F. Elmariami ${ }^{5}$ \\ 1,2,4,5 Department of Electrical Networks and Static Converters, National School of Electricity and Mechanics, \\ ENSEM-Hassan II University of Casablanca, Morocco \\ ${ }^{3}$ LS3M Laboratory, FPK, Hassan 1 University, Morocco
}

\begin{tabular}{l} 
Article Info \\
\hline Article history: \\
Received Oct 24, 2018 \\
Revised Apr 27, 2019 \\
Accepted Jun 26, 2019 \\
\hline Keywords: \\
Distribution power system \\
ENS \\
Graph theory \\
Multi-objective optimization \\
Reclosers \\
Remote controlled switches \\
Reliability \\
SAIDI \\
SAIFI \\
TOPSIS \\
\hline
\end{tabular}

\begin{abstract}
The electrical distribution network is a critical and complex system in terms of safety and reliability, because it is composed of different components (switches, reclosers, etc.). The improvement of its reliability is therefore one of the most important tasks through the good management of remotecontrolled switches and reclosers in this network. This paper presents an analytical model based on graph theory to evaluate SAIDI and SAIFI indices based on the network architecture and the location of remote-controlled reclosers and switches. These indicators have been used to formalize a multiobjective mathematical model that respects the real operation constraints of equipments in smart grid. The applied model, in this article, was evaluated on an IEEE 13 bus network using the TOPSIS method to determine the optimal location of the switches and reclosers and to improve the overall reliability of the distribution network.
\end{abstract}

Copyright $(2019$ Institute of Advanced Engineering and Science. All rights reserved.

\section{Corresponding Author:}

Anass Lekbich,

Department of Electrical Networks and Static Converters,

National School of Electricity and Mechanics (ENSEM-Hassan II University of Casablanca, Morocco),

Road El Jadida, Km 7, BP: 8118, Oasis Casablanca, Morocco.

Email: anass.lekbich@gmail.com

\section{INTRODUCTION}

Power distribution networks need to be more reliable and intelligent due to customer requirements and the complexity of topologies. It's become very complex and operate within normal operating limits [1]. Which requires the using the automatic devices for protection, monitoring and metring that use dedicate communication link $[2,4]$. The reclosers and remote controlled switches have taken a crucial part by network managers to monitor, detect and automatically clear electrical faults and reconfigure distribution networks to reduce the fault number and outage time.

The current situation has encouraged electrical utilities to focus their efforts on improving the reliability of the electricity distribution network [5], which requires significant investments in protection and switching devices such as reclosers, fuses and disconnectors [6]. The tree architecture of the electrical distribution network and the high number of electrical faults put the utilities operator in permanent difficulties. The optimal location of reclosers, switches and protection devices in distribution networks is one of the most effective strategies for increasing reliability and relieving the operator [7]. However, the choice of location remains a complex task requiring non-linear hard NP multi-objective problems using reliability indices based abstract mathematical formula. 
Basically, two approaches can be used to evaluate the reliability indices of the distribution system: analytical formulation and Monte Carlo simulation (MCS) [8]. More importantly, analytical techniques are generally used to evaluate the average values of reliability indicators $[9,10]$ and characterize the difficulty of formulating indicators given the complexity of the architecture of the electricity networks. Monte Carlo simulation is able to provide information on index variability and is flexible enough to accommodate complex operating conditions. But this method requires a very important calculation time per machine [11].

In recently published work, methodologies have been proposed to improve the reliability of the distribution power system by reducing reliability indices, The work [12] has adopted a Monte Carlo simulation approach to assess reliability and cost in a power system using a parallel computing environment, however, and to deal with the problem of evaluation and reliability optimization in a good computation time, researchers have opted for the analytical method based on binary values. In [13], the author minimizes 3 objectives SAIDI, SAIFI and cost using an analytical model however the exact formula of the indicators is not addressed. In [14] a new nonlinear binary programming model aiming at minimizing the reliability indices SAIDI and SAIFI of a distribution feeder this model allows to evaluate with precision the indicators, despite this formula is complex but is very accurate and easy to be used for the optimal location of recloser and switches. In [15], the authors present a multi-objective optimizations to obtain the best reliability of the distribution network while minimizing the costs of the system. In [16], the authors propose an analytical model capable to represent the interactions between the protection and switching devices installed on the electricity distribution network, which makes it possible to optimize the two SAIDI and SAIFI indicators. These works shows that the reliability depends on 3 parameters, an accurate and simple evaluation, the optimization model of the evaluated parameters and finally the equipment used to optimize these indicators.

In this paper the problem is solved in its integrity by using a new formulation of reliability indices based on the graphs the indices are exactly assess in relationship with the location of the remote-controlled swictes and the recloser. The formula clearly describes the optimization problem of reliability by studying the behavior of equipment in the smart grid, the evaluation of these indicators is automatic simple to machinecoded using the force of the adjacent matrix, which allows us to generat a set of scenarios. These scenarios are subsequently treated by TOPSIS.

\section{RESEARCH METHOD}

\subsection{Mathematical modeling of distribution networks}

Distribution networks are generally designed as networks of complex trees with loops, in normal operation, the electrical networks operate in radial architecture. when a fault occure the swiches and recloser change the configuration of electrical networks in order to supply customers while respecting the radiality of the network. From the foregoing considerations, it is possible to represent an electrical distribution network using a tree structure, as shown in Figure 1.

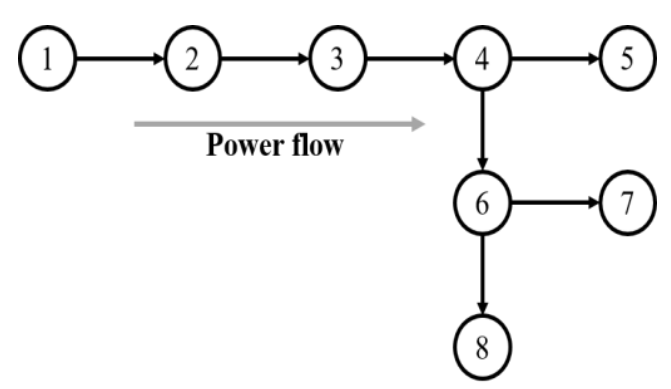

Figure 1. The electrical distribution network presentation

The source of electrical energy is the zone 1 of the graph, the electrical connection between the all areas of the electrical network is presented by arrows representing the direction of the power flow which allows us to define the downstream zones of a given section.

Mathematical model of electrical distribution networks Let $G=\langle V, E\rangle$ be a graph, where $\mathrm{V}$ is a set of $\mathrm{N}$ vertices, and is a set of $\mathrm{M}$ edges between vertices. The adjacent matrix is the matrix representation of the graph representing the topology of the electrical network. 


$A=\left(\begin{array}{llllllll}0 & 1 & 0 & 0 & 0 & 0 & 0 & 0 \\ 0 & 0 & 1 & 0 & 0 & 0 & 0 & 0 \\ 0 & 0 & 0 & 1 & 0 & 0 & 0 & 0 \\ 0 & 0 & 0 & 0 & 1 & 0 & 0 & 0 \\ 0 & 0 & 0 & 0 & 0 & 1 & 0 & 0 \\ 0 & 0 & 0 & 0 & 0 & 0 & 1 & 0 \\ 0 & 0 & 0 & 0 & 0 & 0 & 0 & 1 \\ 0 & 0 & 0 & 0 & 0 & 0 & 0 & 0\end{array}\right)$

(1)

The transposed matrix of $A$ is noted by:

$$
A^{t}=\left(a_{i, j}^{t}\right)
$$

The transitive closure of G, denoted by

$$
\begin{aligned}
A^{*}=\left(a^{*}{ }_{i, j}\right) & 1 \leq i \leq n \\
1 & \leq j \leq n
\end{aligned}
$$

is defined as follows: $a_{i, j}^{*}=1$ if there is a path between vertex $\mathrm{i}$ and vertex $\mathrm{j}$ or $\mathrm{i}=\mathrm{j} ; 0$ otherwise. Figure 2.

The Graph $G^{*}$ transitive closure of $G$ and the matrix $A^{*}$ presentation of the $G^{*}$ are shown in

$$
A^{*}=\left(\begin{array}{cccccccc}
1 & 1 & 1 & 1 & 1 & 1 & 1 & 1 \\
0 & 1 & 1 & 1 & 1 & 1 & 1 & 1 \\
0 & 0 & 1 & 1 & 1 & 1 & 1 & 1 \\
0 & 0 & 0 & 1 & 1 & 1 & 1 & 1 \\
0 & 0 & 0 & 0 & 1 & 0 & 0 & 0 \\
0 & 0 & 0 & 0 & 0 & 1 & 1 & 1 \\
0 & 0 & 0 & 0 & 0 & 0 & 1 & 0 \\
0 & 0 & 0 & 0 & 0 & 0 & 0 & 1
\end{array}\right)
$$

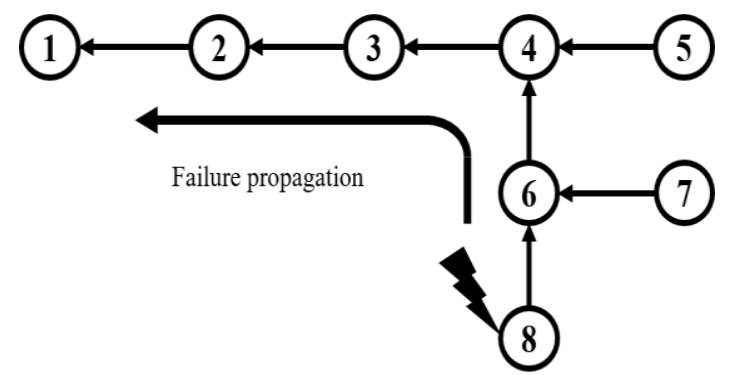

Figure 2. Failure propagation

$A^{* t}$ the transposed matrix of the adjacent matrix $\mathrm{A}^{*}$ of a graph. It determines the elements $\mathrm{j}$ of the predecessor electrical network of the sections i denoted P. Fig 2 shows the graph of failure propagation which groups the upstream zones of the fault zone. 


\subsection{Formulation of the problem}

To represent the location of remote controlled switches and reclosers in the radial distribution network, the discrete variables were used to indicate the installation of the recloser or RCS in a section $i$ of the power grid and are defined as follows [9]:

$$
\begin{aligned}
& X_{i}=\left\{\begin{array}{lcccc}
0 & \text { if } & a & \text { recloserin } & i \\
1 & & \text { if } & \text { not }
\end{array}\right. \\
& Y_{i}=\left\{\begin{array}{lllll}
0 & \text { if } & & a & \text { RCS in } \\
1 & & \text { if } & \text { not }
\end{array}\right.
\end{aligned}
$$

The location matrix is defined as follows:

$$
\begin{gathered}
P_{x}=\left(p_{i, j}\right)_{\substack{1 \leq i \leq n \\
1 \leq j \leq n}}=\left(a^{t}{ }_{i, j} \cdot x_{i}\right)_{\substack{1 \leq i \leq n \\
1 \leq j \leq n \\
1 \leq j}} \\
P_{y}=\left(p_{i, j}\right)_{\substack{1 \leq i \leq n \\
1 \leq j \leq n}}=\left(a^{t}{ }_{i, j} \cdot y_{i}\right)_{\substack{1 \leq i \leq n \\
1 \leq j \leq n}}
\end{gathered}
$$

The transitive closure of $P_{x}$ is noted by $P_{x}^{*}$ and the transitive closure of $P_{y}$ is noted by $P_{y}^{*}$.

The two matrices $P_{x}^{*}$ and $P_{y}^{*}$ respectively express the paths connecting the area of the electrical network to the upstream zones through the recloser and the remote controlled switch, which will allow us to define the protected area in the electrical networks. They are used to precisely locate areas protected by cut-off devices in the radial network.

Figure 3 shows in red the failure propagation between sections $i$ and $j$ caused by a fault in $i$. The current faults propagates in the upstream zones and generates an electrical faults in the zones downstream of all the zones affected by the faults.

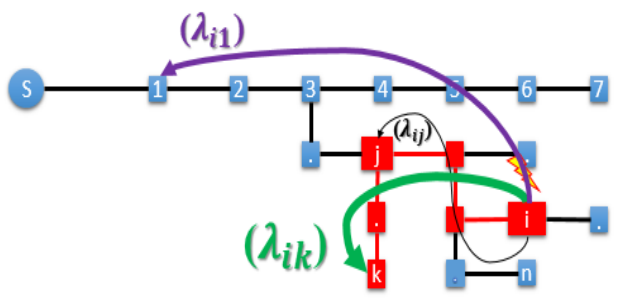

Figure 3. The fault rate in electrical networks

The $\lambda_{i j}$ describes the fault rate in $\mathrm{j}$ caused by fault in $\mathrm{i}$.

The fault rate is limited by the location of the recloser, however the use of a remote controlled switch minimizes the outage time by the fast and automatic isolation of the sections affected by the fault. Figure 4 shows the Failure propagation in electrical networks with and without recloser.

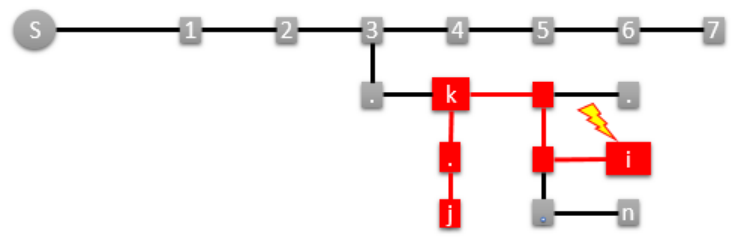

$C(i, j)=1 \Rightarrow$ The Load $\mathbf{j}$ is not protected against fault in $\mathbf{i}$

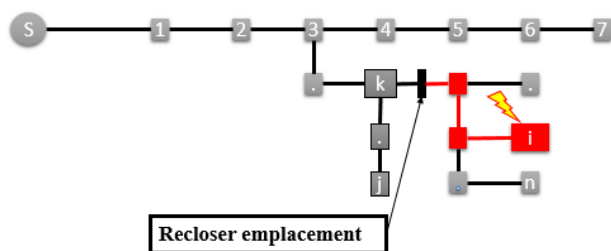

$C_{x}(i, j)=0 \Rightarrow \quad$ The load $\mathbf{j}$ is protected against fault in $\mathbf{i}$

Figure 4. Failure propagation in electrical networks with and without recloser 
If we use a recloser in the path between the fault location and power source, the default propagation must be limited to the downstream area of the recloser.

In order to detect all sections of the power grid affected by the fault, we define the matrix as follows:

$$
P_{x}^{*} \cdot A^{*}=C_{x}(i, j)
$$

If we use a remote controlled switch in the path between the fault location and power source, the fault propagation must be limited to the downstream area of the remote controlled switches.

$$
P_{y}^{*} A^{*}=C_{y}(i, j)
$$

If $C_{X}(i, j) \neq 0$, it means that the $\mathrm{j}$ is not protected against fault with recloser/switch from the fault in i. If $C_{X}(i, j)=0$ it means that a recloser/switch is installed in the path between i and j. Evaluation of repair time and fault rate in radial feeder networks. If $a_{i, j}^{*}=1$, this implies that the load $\mathrm{j}$ is downstream of the section $\mathrm{i}$ of the electrical network, each fault in $\mathrm{i}$ generates a power outage in $\mathrm{j}$ and the restored electrical power is related to the repair of the section $i$.

In this case, the fault rate and the repair time are identical in all the sections $\mathrm{j}$.

$$
\begin{aligned}
& \lambda_{i j}=\lambda_{i} \\
& r_{i j}=r_{i}
\end{aligned}
$$

If $a_{i, j}^{*}=0$, it means that the load $\mathrm{j}$ is downstream of the section $\mathrm{i}$ of the electrical network, the installation of the reclose rans Remote controlled switches will make possible to isolate the faulty section i. and decrease the outage time.

$$
\begin{aligned}
& \lambda_{i j}=\lambda_{i} \cdot C_{x}(i, j) \\
& r_{i j}=r_{i} \cdot C_{x}(i, j)+r_{i s o, i} \cdot C_{y}(i, j)
\end{aligned}
$$

\subsection{Formulation of reliability indices}

To evaluate the reliability of electricity grids, many indices are used by utilities, according to IEEE Std 1366- 2012 [17]. Power utilities frequently use SAIDI and SAIFI to assess the reliability of the power grid. The (SAIDI) gives the average interruption time per consumer for one year and the (SAIFI) gives the average of the system index of the frequency of interruptions [18].

$$
\begin{array}{r}
\text { SAIDI }=\frac{\sum_{i=1}^{n} \sum_{j=1}^{n} \lambda_{i j} \cdot r_{i j} \cdot N_{i}}{\sum_{i=1}^{n} N_{i}} \\
\text { SAIFI }=\frac{\sum_{i=1}^{n} \sum_{j=1}^{n} \lambda_{i j} \cdot N_{i}}{\sum_{i=1}^{n} N_{i}}
\end{array}
$$


These indices depend on the ability of the protection devices to eliminate faults as quickly as possible and to reconfigure the network topology and strongly related on the location of the reclosers and the remote controlled switches. We replace the fault rates (13) and repair times (14) by their formulas for getting the formulations of SAIDI and SAIFI.

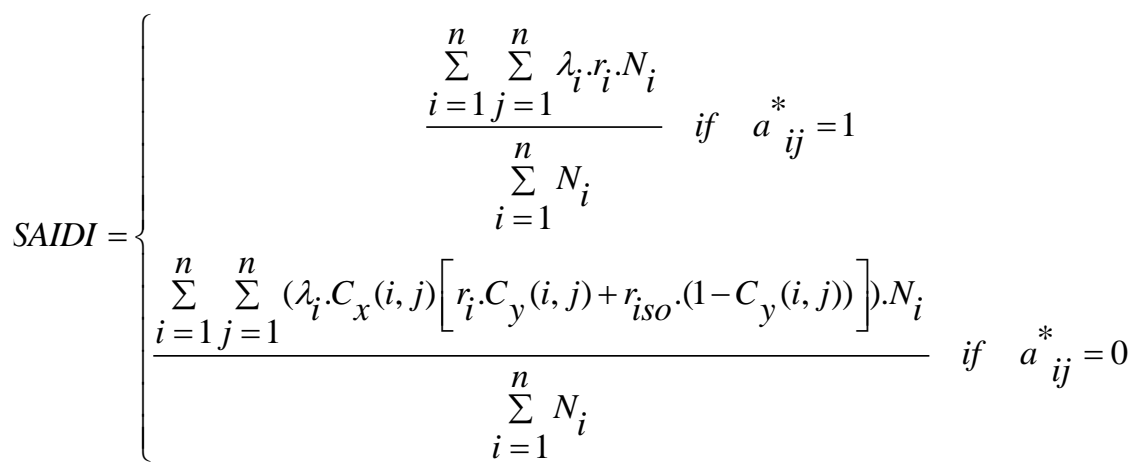

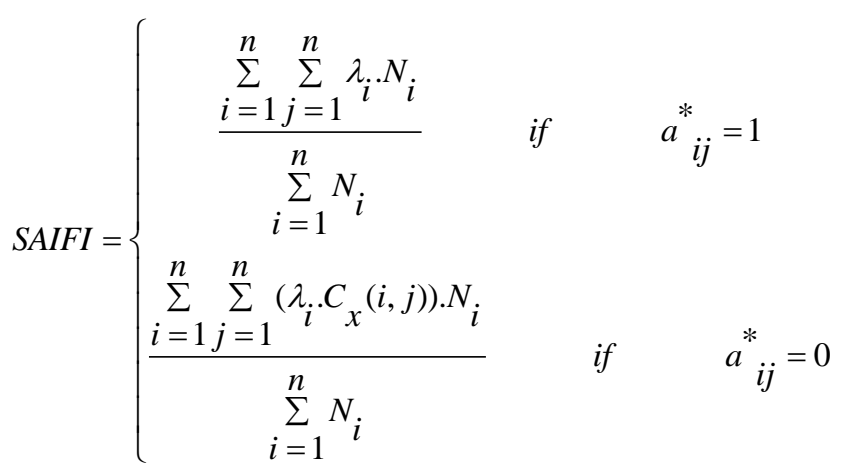

\subsection{Formulation of cost function}

All decision made by the electrical network engineers to minimize the reliability indices required investments to either the equipments level or the annual maintenance of the equipments [19].The optimal solution that improves the reliability of the electrical distribution system through a set of decisions involving the use of protections and switches devices by an acceptable price remains one of the challenges. The notion of cost is paramount for investments given the complexity of the proposed solutions and the limitation of resources for most energy distributors operating in a competitive market [20].

The cost of the solution is the sum of the fixed costs associated with capital investment on switches and protection devices and the cost of interruptions [21]. This cost is described by the following equation:

$$
\text { Cost }=F C+C t * E N S
$$

ENS is the total not distributed energy described as follows:

$$
E N S=\sum_{i=1}^{n} L_{i} \cdot \sum_{j=1}^{n} \lambda_{i j} . r_{i j}
$$

$\mathrm{Ct}$ is the cost of energy, in this paper $\mathrm{Ct}=0,079$ euro/kwh. $\mathrm{FC}$ : the cost of purchasing equipment (switches and reclosers) in euro including maintenance.

\subsection{Constraints}

To choose the location of the swiches ans reclosers in electrical networks, functional constraints must be taken into account to limit the search space and focus on the feasible scenarios; the maximum number of reclosers in line, the coordination between equipments and the location of the switches relative to the recloser. 
One of the most important constraints of the objective function is the coordination of protection devices (reclosers). The number of devices that can be installed in series is limited for the purpose of maintaining coordination [22]. In this article the maximum number of reclosers in series is limited to 3 to exploit the maximum functionality of the equipment in an optimal coordination level [15].

\subsection{Multicriteria decision analysis based on the TOPSIS method}

To determine the number and location of switches devices in a distribution network, we will need a multi-criteria decision analysis method; TOPSIS is one of the most widely used multi-criteria decision analysis methods [23], [24]. This method ranks the alternatives according to the proximity between the alternatives and the ideal alternatives, which are obtained by calculating the distance of the alternatives from the positive ideal and the ideal negative alternatives.

The Specific steps of TOPSIS method:

STEP 1: is to establish a decision matrix for the ranking. The structure of the matrix can be expressed as follows[24]:

$C_{1}$
$A_{1}$
$A_{2}$
$A_{3}$
$\ldots$
$A_{m}$$\quad\left(\begin{array}{ccccc}z_{11} & c_{2} & C_{3} & \ldots \ldots & C_{n} \\ z_{21} & z_{22} & z_{13} & \ldots & z_{1 n} \\ z_{31} & z_{32} & z_{33} & \ldots & z_{2 n} \\ \ldots & \ldots & \ldots & \ldots & z_{3 n} \\ z_{m 1} & z_{m 2} & z_{m 3} & \ldots & z_{m n}\end{array}\right)$

In decision matrix, $A_{i}$ denotes the alternatives $i, i=1,2, \ldots, \mathrm{m} . C_{j}$ represents $j^{\text {th }}$ criteria, related to $i^{\text {th }}$ alternative. $z_{i j}$ is the performance ratings for each alternative $A_{i}$ with respect to each criteria $C_{j}$.

STEP 2: Calculation of the normalized decision matrix R using normalization vector:

$$
\begin{array}{r}
R=\left(r_{i j}\right) 1 \leq i \leq m \\
1 \leq j \leq n
\end{array}
$$

Where

$$
r_{i j}=\frac{z_{i j}}{\sqrt{\sum_{i=1}^{n} z^{2} i j}}
$$

STEP 3: Calculation of the weighted normalized matrix $\mathrm{V}$ by multiplying the columns of the normalized decision matrix $\mathrm{R}$ by the associated weights $w_{j} \in \mathfrak{R}$ satisfying

$$
\begin{aligned}
& \sum_{j=1}^{n} w_{j}=1 ; \\
& V=\left(v_{i j}\right)_{\substack{1 \leq i \leq n \\
1 \leq j \leq m}}
\end{aligned}
$$

where :

$$
v_{i j}=r_{i j} \cdot w_{j}
$$

Depending on the purpose and the decision-makers, different evaluation criteria have different weights, hence the need to calculate the weighted normalized decision matrix [25]. 
STEP 4: Determination of the positive ideal solution PIS and of the negative ideal solution NIS.

The PIS is the one with the best level for all of the attributes considered. The NIS is the one with the worst attribute values.

STEP 5: Calculation of the Euclidean distances of each alternative $A_{i}$ from the positive ideal solution PIS and from the negative ideal solution NIS:

$$
d_{i}^{-}=\sqrt{\sum_{j=1}^{n}\left(v_{i j}-v_{j}^{-}\right)^{2}}
$$

and,

$$
d_{i}^{+}=\sqrt{\sum_{j=1}^{n}\left(v_{i j}-v_{j}^{+}\right)^{2}}
$$

The relative closeness to the ideal solution is calculated, and the ranking of the alternatives in descending order is done. The closeness coefficient of each alternative is calculated as follows [26]:

$$
C C_{i}=\frac{d_{i}^{-}}{d_{i}^{+}+d_{i}^{-}}
$$

The ranking of alternatives is determined by comparing $C C_{i}$ values.

\section{RESULTS AND ANALYSIS}

\subsection{Implementation and solving using topsis}

In order to test the impact of the location of reclosers and switches devices on the reliability indicators and to choose the optimal solution, we used the IEEE 13 bus network. The table below lists the different electrical values of the IEEE 13 bus. For each branch of this network we propose a variable repair time of 3 to 6 hours as shown in Table 1, this time is linked to the permanent fault and a fixed isolation time of $0.08 \mathrm{~h}$ corresponding to the recloser intervention time to eliminate the transient faults.

Table 1. Lists the different electrical values of the IEEE 13 bus

\begin{tabular}{cccccc}
\hline Branch & Li (KVA) & N of Customer & Fault rate & Repaire time & Isolement time \\
\hline 1 & 0 & 0 & 0,1 & 3 & 0,08 \\
2 & 0 & 0 & 0,15 & 4 & 0,08 \\
3 & 150 & 55 & 0,2 & 6 & 0,08 \\
4 & 630 & 80 & 0,25 & 3 & 0,08 \\
5 & 220 & 200 & 0,15 & 2 & 0,08 \\
6 & 720 & 47 & 0,1 & 2 & 0,08 \\
7 & 445 & 10 & 0,1 & 4 & 0,08 \\
8 & 30 & 4 & 0,15 & 5 & 0,08 \\
9 & 340 & 10 & 0,2 & 6 & 0,08 \\
10 & 400 & 117 & 0,25 & 3 & 0,08 \\
11 & 630 & 145 & 0,15 & 3 & 0,08 \\
12 & 1250 & 70 & 0,1 & 2 & 0,08 \\
13 & 630 & 0,1 & 2 & 0,08 \\
\hline
\end{tabular}

\subsection{SAIDI and SAIFI calculation}

In this case we use 2 reclosers in section 2; 7 and a remote controlled switch in 4 . The Figure 5 shows the fault rate matrix after allocation of 2 reclosers and remote a controlled switch. After the calculation of fault rate matrix and the time outage matrix using the (13) and (14) formula, we shown in Figure 5 that the fault rate matrix depende on the location of renclencheurs. The outage time matrix rij the depende on remote controlled switch placement. Using the formula (17) and (18) the SAIDI and SAIFI are given below:

$$
\text { SAIDI }=6,1726 \mathrm{~h} / \text { year } \quad \mathrm{SAIFI}=1,5724 \text { fault/year }
$$




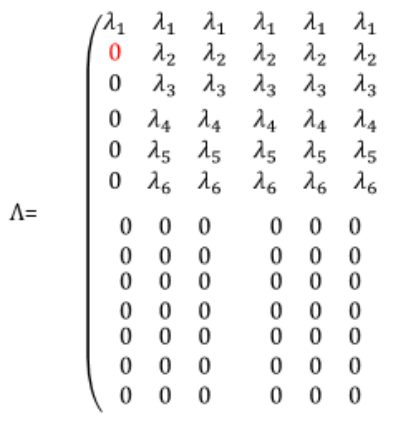

$\begin{array}{lllllll}\lambda_{1} & \lambda_{1} & \lambda_{1} & \lambda_{1} & \lambda_{1} & \lambda_{1} & \lambda_{1}\end{array}$

$\begin{array}{lllllll}\lambda_{2} & \lambda_{2} & \lambda_{2} & \lambda_{2} & \lambda_{2} & \lambda_{2} & \lambda_{2}\end{array}$

$\begin{array}{lllllll}\lambda_{3} & \lambda_{3} & \lambda_{3} & \lambda_{3} & \lambda_{3} & \lambda_{3} & \lambda_{3}\end{array}$

$\begin{array}{lllllll}\lambda_{4} & \lambda_{4} & \lambda_{4} & \lambda_{4} & \lambda_{4} & \lambda_{4} & \lambda_{4}\end{array}$

$\begin{array}{lllllll}\lambda_{5} & \lambda_{5} & \lambda_{5} & \lambda_{5} & \lambda_{5} & \lambda_{5} & \lambda_{5}\end{array}$

$\begin{array}{lllllll}\lambda_{6} & \lambda_{6} & \lambda_{6} & \lambda_{6} & \lambda_{6} & \lambda_{6} & \lambda_{6}\end{array}$

$\begin{array}{lllllll}\lambda_{7} & \lambda_{7} & \lambda_{7} & \lambda_{7} & \lambda_{7} & \lambda_{7} & \lambda_{7}\end{array}$

$\begin{array}{lllllll}\lambda_{8} & \lambda_{8} & \lambda_{8} & \lambda_{8} & \lambda_{8} & \lambda_{8} & \lambda_{8}\end{array}$

$\begin{array}{lllllll}\lambda_{9} & \lambda_{9} & \lambda_{9} & \lambda_{9} & \lambda_{9} & \lambda_{9} & \lambda_{9}\end{array}$

$\begin{array}{lllllll}\lambda_{10} & \lambda_{10} & \lambda_{10} & \lambda_{10} & \lambda_{10} & \lambda_{10} & \lambda_{10}\end{array}$

$\begin{array}{lllllll}\lambda_{11} & \lambda_{11} & \lambda_{11} & \lambda_{11} & \lambda_{11} & \lambda_{11} & \lambda_{11}\end{array}$

$\begin{array}{lllllll}\lambda_{12} & \lambda_{12} & \lambda_{12} & \lambda_{12} & \lambda_{12} & \lambda_{12} & \lambda_{12}\end{array}$

$\left.\begin{array}{lllllll}\lambda_{13} & \lambda_{13} & \lambda_{13} & \lambda_{13} & \lambda_{13} & \lambda_{13} & \lambda_{13}\end{array}\right)$

IEEE 13 Bus

Figure 5. The fault rate matrix

\subsection{Solving the optimisation problem using TOPSIS}

In this study, a multi-objective approach to improve the reliability of the power grids was proposed and presented in Figure 6 and it was evaluated by a succession of simulations of a program implemented on MATLAB. Based on data of the Table 2 the Table 3 summarizes all results of the proposed method solved by TOPSIS. It groups together 15 randomly selected scenarios. These scenarios respect the optimization constraints of the problem. The weights of the objectives are considered identical and equal to 0.33 and this makes it possible to make a decision based on the importance of the objectives.

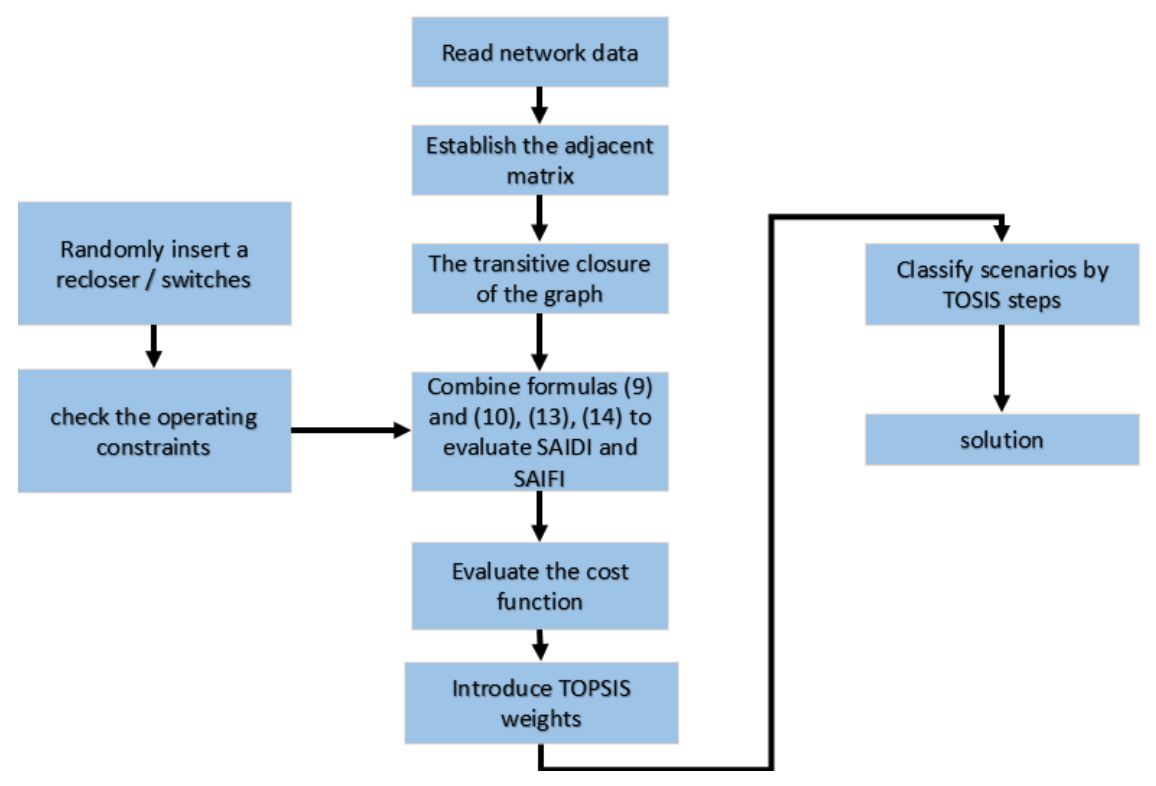

Figure 6. Flowchart of the solution

Table 2.The annual cost of breaking devices inclusding the maintenance

\begin{tabular}{cc}
\hline Device & Cost(euro/Year) \\
\hline Recloser & 6000 \\
Remote controlled switch & 2500 \\
\hline
\end{tabular}




\begin{tabular}{|c|c|c|c|}
\hline & Location of recloser & Location of RCS & Cci \\
\hline $\mathrm{S} 1$ & 1 & $5 ; 8 ; 11$ & 0,238708312312 \\
\hline $\mathrm{S} 2$ & $1 ; 5$ & $7 ; 11$ & 0,305864790650 \\
\hline S3 & $3 ; 8$ & 5 & 0,367792744184 \\
\hline $\mathrm{S} 4$ & $1 ; 6 ; 7$ & 11 & 0,362636079079 \\
\hline S5 & $1 ; 8 ; 11$ & $6 ; 7$ & 0,384202788741 \\
\hline S6 & 1 & $7 ; 8$ & 0,224218416516 \\
\hline S7 & $1 ; 8 ; 11$ & $6 ; 13$ & 0,382044331560 \\
\hline S8 & $1 ; 8 ; 11$ & $7 ; 13$ & 0,389774195945 \\
\hline S9 & $1 ; 11$ & $7 ; 8$ & 0,271773052270 \\
\hline S10 & $6 ; 9 ; 13$ & $7 ; 11 ; 12$ & 0,476612015637 \\
\hline S11 & $2 ; 5$ & $8 ; 11$ & 0,359388826131 \\
\hline $\mathrm{S} 12$ & $1 ; 7 ; 8 ; 11$ & 4 & 0,492740199948 \\
\hline $\mathrm{S} 13$ & $4 ; 7 ; 8 ; 11$ & $5 ; 6 ; 13$ & 0,671437126953 \\
\hline S14 & 3 & -- & 0,358417236519 \\
\hline $\mathrm{S} 15$ & 3 & $4 ; 7 ; 8 ; 11$ & 0,414252992138 \\
\hline
\end{tabular}

The best scenario according to the TOPSIS method is scenario number 6 see the Table 4 . The advantage of our method is the flexibility in terms of decision making as well as the simplicity of implementation on machine, we can manipulate several objectives and choose different weight. The optimal location of reclosers and switches corresponding to the best objective functions value are chosen as the final solution in IEEE 13 bus the best solution are a recloser in 1 and 2 switches in 7 and 8 .

Table 4. The best scenario according to the TOPSIS

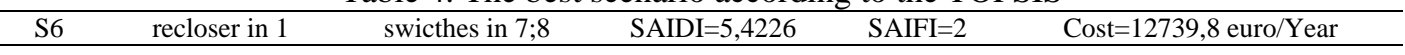

\section{CONCLUSION}

In this article, we have proposed an analytical model to evaluate the two reliability indices SAIDI and SAIFI. This simple machine-implemented model uses the adjacent matrix to determine fault propagation paths, which allows accurate evaluation of fault rates and repair times for each network area. After evaluation of the reliability indices, a multi-objective mathematical model is proposed to find the optimal location of the switches and reclosers using the TOPSIS method. Since the multi-objective problem is a difficult problem and takes a long time to resolve, the TOPSIS method breaks many senarios that respect the exploitation constraints and solves the problem of improving the reliability via the positioning of reclosers and the location of switches in an efficient calculation time.

\section{REFERENCES}

[1] Dazahra M N, Elmariami F, Belfqih A, Boukherouaa J., "Smart Local Backup Protection For Smart Substation," International Journal of Electrical and Computer Engineering (IJECE); vol. 7, no. 5, pp. 2321-2328, Oct 2017.

[2] Dragan M, Srete N, Emir A., "Designing Automatic Meter Reading System Using Open Source Hardware and Software," International Journal of Electrical and Computer Engineering (IJECE), vol 7, no. 6, pp. 3282-3291, Dec 2017.

[3] Lekbich A, Belfqih A, Zedak C ,Boukherouaa J , Mariami F, "A secure wireless control of Remote Terminal Unit using the Internet of Things in smart grid," 6th International Conference on Wireless Networks and Mobile Communications (WINCOM), 2018.

[4] Zedak C, Lekbich A, Belfqih A, Boukherouaa J, Haidi T, Mariami F, "A proposed secure remote data acquisition architecture of photovoltaic systems based on the Internet of Things," 6th International Conference on Multimedia Computing and Systems (ICMCS), 2018.

[5] Venkata S B K, Madhusudan V, Ganesh V, "Probabilistic Performance Index based Contingency Screening for Composite Power System Reliability Evaluation," International Journal of Electrical and Computer Engineering (IJECE), vol. 8, no. 5, pp. 2661-2670, Oct 2018.

[6] Kumar KS, Jayabarathi T, "Power system reconfiguration and loss minimization for an distribution systems using bacterial foraging optimization algorithm," Int J Electr Power Energy Syst, vol. 36, no. 1, pp. 13-17, 2012.

[7] R. Billinton, P. Wang, "Teaching distribution system reliability evaluation using Monte Carlo simulation," IEEE Trans. Power Syst., vol. 14, no. 2, pp. 397-403, May 1999.

[8] Chitumodhu B, Renuka L, "An open source tool for reliability evaluation of distribution system using Monte Carlo simulation," Indonesian Journal of Electrical Engineering and Computer Science (IJEECS), vol. 14, no. 3, pp. 1065-1075, Jun 2019.

[9] Zambon E, Bossois DZ, Garcia BB, Azeredo EF, "A novel nonlinear programming model for distribution protection optimization," IEEE Trans Power Delivery 2009, vol. 24, pp. 1951-8, 2009. 
[10] Yeh WC, Lin YC, Y.Chung Y, Chih M, "A particle swarm optimization approach based on Monte Carlo simulation for solving the complex network reliability problem," IEEE Trans. Reliab, vol. 59, no. 1, pp. 212-221, 2010.

[11] Zhenga H, Chenga Y, Goub B, Frankc D, Bernc A, Mustonc W.E, "Impact of automatic switches on power distribution system reliability," Electric Power Systems Research, vol. 83, pp. 51-57, 2012.

[12] Haifenga G, Asgarpoor Sohrab, "Parallel Monte Carlo simulation for reliability and cost evaluation of equipment and systems," Electr Power Syst Res, vol. 81, no. 2, pp. 347-56, 2011.

[13] Vieira AP, Murta JP, Fernão VP, "Multiobjective planning of distribution networks incorporating switches and protective devices using a memetic optimization," Reliability Engineering and System Safety, vol. 136, pp. 101-108, 2015.

[14] Ferreira GD, Bretas ASA, "Nonlinear binary programming model for electric distribution systems reliability optimization," Electrical Power and Energy Systems, vol. 43, pp. 384-392, 2012.

[15] Wiwat T, Dulpichet R, "Multiobjective optimal placement of switches and protective devices in electric power distribution systems using ant colony optimization," Electric Power Systems Research, vol. 79, pp. 1171-1178, 2009.

[16] Soudi F, Tomsovic K,"Optimized distribution protection using binary programming," IEEE Trans. Power Del., vol. 13, no. 1, pp. 218-224, Jan 1998.

[17] "IEEE guide for electric power distribution reliability indices," IEEE Std. 1366, 2012.

[18] Subramanya SS, Madhusudhan V, Ganesh V, "Reliability worth Assessment of Active Distribution System Considering Protective Devices and Multiple Distributed Generation Units," International Journal of Applied Power Engineering (IJAPE), vol. 7, no. 2, pp. 111-119, Aug 2018.

[19] Kela KB, Bhavik NS ,Arya LD, "Reliability optimization of electrical distribution systems considering expenditures on maintenance and customer interruptions," Indonesian Journal of Electrical Engineering and Computer Science (IJEECS), vol. 14, no. 3, pp. 1057-1064, Jun 2019.

[20] Dezaki HH, Hosseinian SH, "Optimized operation and maintenance costs to improve system reliability by decreasing the failure rate of distribution lines," Turk. J. Elec. Eng. \& Comp. Sci., vol. 21, pp. 2191-2204, 2013.

[21] Heinrich C, "Calculation of network improvement of feeder upgrade by reclosers, sectionalisers and other distribution equipment," 8th International Conference on Advances in Power System Control, Operation and Management (APSCOM 2009), Hong Kong, China, Nov 2009.

[22] Sohn JM, Nam SR, Park JK, "Value-based radial distribution system reliability optimization," IEEE Trans Power Syst, vol. 21, pp. 94, 2006.

[23] Guowang L,Yanmin L, Xiaoling M, "Factor Analysis Model Based on the Theory of the TOPSIS in the Application Research," Discrete Dynamics in Nature and Society, vol. 2017, 2017.

[24] Lam WH, Lam WS, Liew KF, "Performance analysis on telecommunication companies in malaysia with TOPSIS model," Indonesian Journal of Electrical Engineering and Computer Science (IJEECS), vol. 13, no. 2, pp. 744-751, Feb 2019.

[25] Emil B, Tomo S, Tomislav V, "Optimal Wireless Network Selection Following Students Online Habits Using Fuzzy AHP and TOPSIS Methods," Wireless Communications and Mobile Computing Conference(IWCMC), 2015.

[26] Dariusz W, Aleksandra R, "Project rankings for participatory budget based on the fuzzy TOPSIS method," European Journal of Operational Research, vol. 260, pp. 706-714, 2017.

\section{BIOGRAPHIES OF AUTHORS}

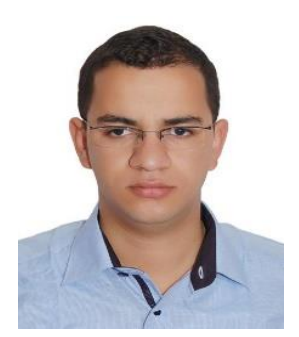

Anass Lekbich: Phd student at the National School of Electricity and Mechanics (ENSEM Hassan II University of Casablanca), was born in Morocco on the 19th of November 1988. He got his Eng. Degree from ENSEM - Hassan II University of Casablanca, in 2012, since 2015. His research interests include electrical networks, distribution system, reclosers and swiches placement, SCADA system and smart grid.

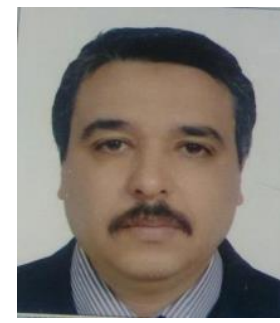

Pr. Abdelaziz Belfqih: Professor Ability to Direct Research at the National School of Electricity and Mechanics (ENSEM - Hassan II University of Casablanca). Doctor Engineer and holder of HDR. RECS Research Team Leader. Currently working on Electrical networks. 


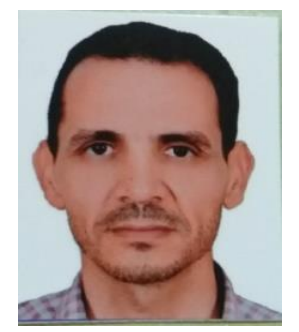

Pr. Tayeb Ouaderhman: Assistant professor at Hassan 1 University of Settat morocco. $\mathrm{PhD}$ on Operation research. Actualy working on multicreteria decision making and machine learning. Email : tayeb.ouaderhman@uh1.ac.ma

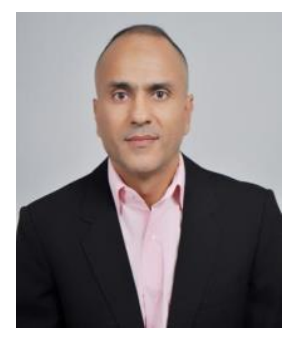

Pr. Jamal Boukherouaa: Professor Ability to Direct Research at the National School of Electricity and Mechanics (ENSEM - Hassan II University of Casablanca). Doctor Engineer and holder of HDR. RECS Research Team Leader. Currently working on high-frequency static converters.



Pr. Faissal El Mariami: Professor Ability to Direct Research at the National School of Electricity and Mechanics (ENSEM - Hassan II University of Casablanca). Doctor Engineer and holder of HDR. RECS Research Team Leader.Currently working on Location of FACTS in Electrical networks. 